\title{
Preventing nickel allergy using various topcoats for decorative items
}

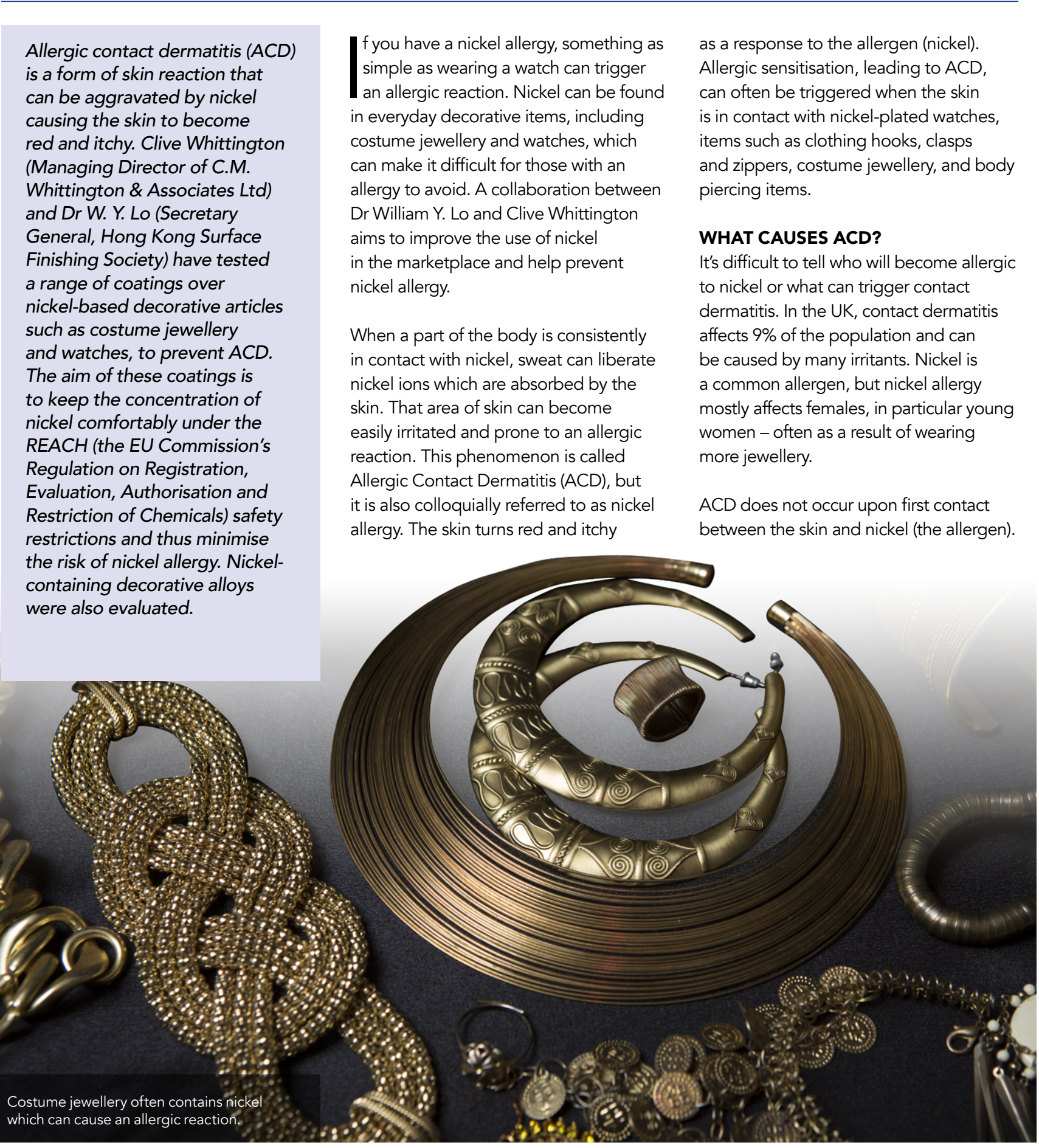

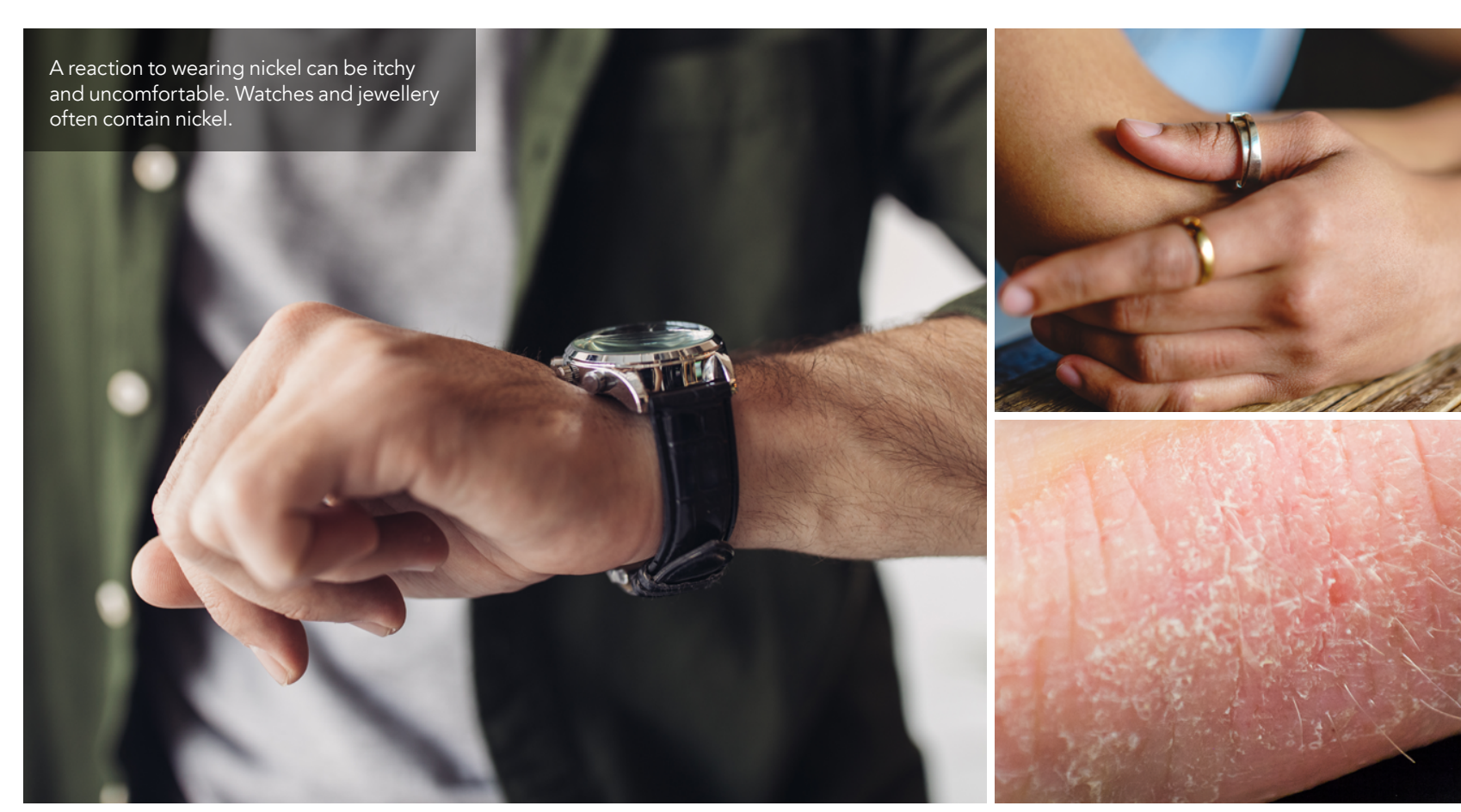

Instead, the body becomes sensitised, but may not react immediately. When the
skin is further exposed to nickel, the nowsensitised body treats it as an allergen and the immune system reacts. The response to the nickel causes the skin to become red and itchy. Once the item containing nickel is removed, ACD symptoms will start to dissipate. The degrees of allergic response differ greatly from person

to person.

Clive Whittington and Dr William Lo evaluated non-nickel surface coatings which enable nickel-containing consu products to be safely placed on the market whthout concen for nickel pecific regultions covered by the EU 'Nickel Restrictions' which impose limits on the amount of nickel released from articles intended to come into direct and prolonged contact with skin (like the back of a watch).

In the tests run by Whittington and Lo, each coating was measured for nickel release according to the CEN (Comité Européen de Normalisation, European Committee for Standardization) nicke tests for coated items: EN 12472 (for wear and corrosion) and EN 1811 (for the determination of nickel release). The CEN tests require that nickel release should not exceed $0.5 \mu \mathrm{g} \mathrm{cm}^{-2}$ week after two years of normal use. However,
Sweat from the skin can liberate nickel ions which are absorbed by the skin and initiate an allergic response

an article is compliant if nickel release is $<0.88 \mathrm{\mu g} \mathrm{cm}^{-2}$ week-1 after two years and can be placed on the market.

Since costume jewellery is usually made from cheaper metals and plated with nickel, these items are more likely to trigger nickel ACD in sensitised person topeor, to pre is a need for efficient these decorative items in particular.

COATINGS FOR NICKEL-BASED DECORATIVE ITEMS

COATINGS FOR NICKEL-BASED and Lo look at using different coatings that prevent the release of nickel from nickel-based decorative items on the market. They tested non-nickel surface coatings including gold alloys, coloured and uncoloured topcoats against nickel release and found most coatings succeeded in preventing nickel release well within the CEN nickel-release limits. CHROMIUM TOPCOATS In their initial tests, the authors found that regular chromium deposited from a hexavalent electrolyte, microporo electrolyte, and ultraviolet (UV) cured polyurethane electrophoretic coatings prevent nickel release when applied according to the relevant Internation

hexavalent chromium electrolytes are constrained in many jurisdictions due to environmental concerns. Trivalent chromium electrolytes therefore present an effective alternative.

SULPHUR-CONTAINING BRIGHT NICKEL WITH FLASH GOLD DEPOSITS Whittington and Lo also tested electrodeposits of sulphur-containing bright nickel on pieces of costume jewellery and determined that nickel ons were released at a rate exceeding acceptable CEN limits. A thin, porous same items also failed the tests, since the thin coating of gold significantly figures exceeding the CEN limits. On the other hand, an uncoated gold alloy

METAL SURFACE COATINGS Costume jewellery and watch cases flash topcoat of gold applied over the accelerated the release of nickel to containing $6 \%$ nickel passed the CEN 


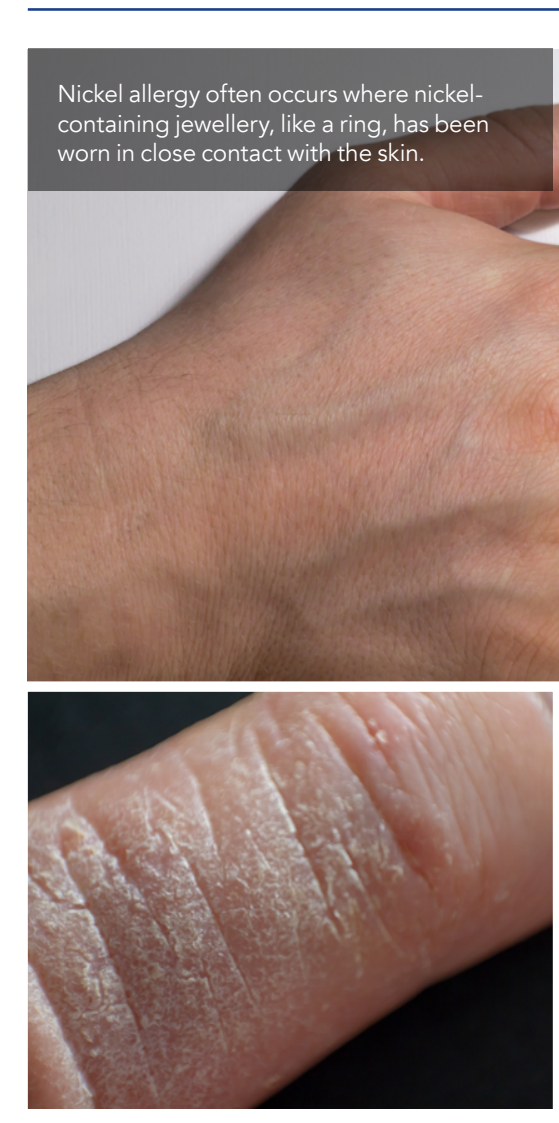

having an electrodeposited palladium barrier coating (either as a topcoat or prevented nickel release and kept it within CEN limits successfully.

NICKEL-CONTAINING AUSTENITIC STAINLESS-STEEL WATCH CASES For this test, Whittington and Lo utilised watch cases made of nickel-containing stainless steel (Grades 304 and 316). They masked off the areas of the watch case that did not come into contact when uncoated and also colted with a very thin Physical Vapour Deposition Titanium Nitride (PVD TiN) coating. Both the uncoated and coated watch cases passed the CEN nickel release tests comfortably.

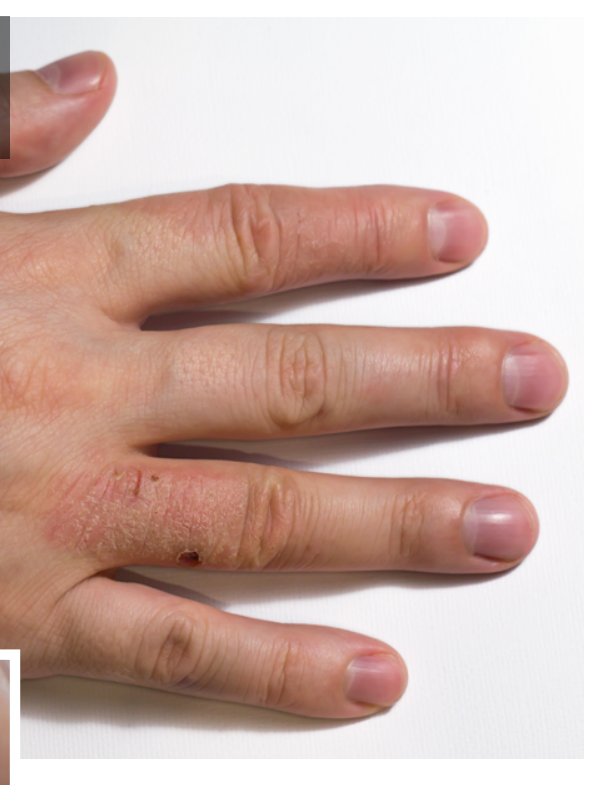

WHAT'S A PVD TIN COATING AND HOW IS IT APPLIED?

PVD TiN refers to a Titanium Nitride

(TiN) coating applied by a process called

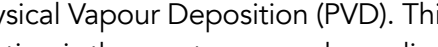

PVD coating because it is durable

inert, adherent and can be easily,

stripped and recoated if needed. A

PVD TiN coating has several uses and

COATINGS CAN BE

COLOURED TOO...

As well as looking at the different

Whe

Whittington and Lo also tested different

colours that could be applied to

topcoats to give the effect needed. For example, organic non-nickel topcoats may be dyed to produce a variety of colours in the surface finish of the iten The results from these tests showed that most coatings passed the CEN tests and did not exceed the nicke release limits.

Nickel is one of the most common metals used in costume jewellery and widch cases. As nickel allergy is so coatings could be used to prevent nickel release is extremely significan

The researchers found regular hexavalent chromium, microporous trivalent chromium from a chloride electrolyte, ultraviolet (UV) cured polyurethane electrophoretic coatings

The EU 'Nickel Restrictions' impose limits on the amount of nickel released from articles.

is currently used on many expensive and an electrodeposited palladium tools, medical (implanting and surgical) instruments, food processing and by vaporising the material from applied source in the form of atoms/moleclits and then transporting it in the form of vapour through a vacuum, low-pressur gas or plasma to the substrate (e.g. a watch case) where it condenses and coats the item. Additionally, nickel-containing stainless seel with or without a PVD TiN coating readily passed the CEN nickel release ests. The results of this work mean hese coatings and alloys can be used for decorative articles that are sold in the market without concern bout nickel release exceeding

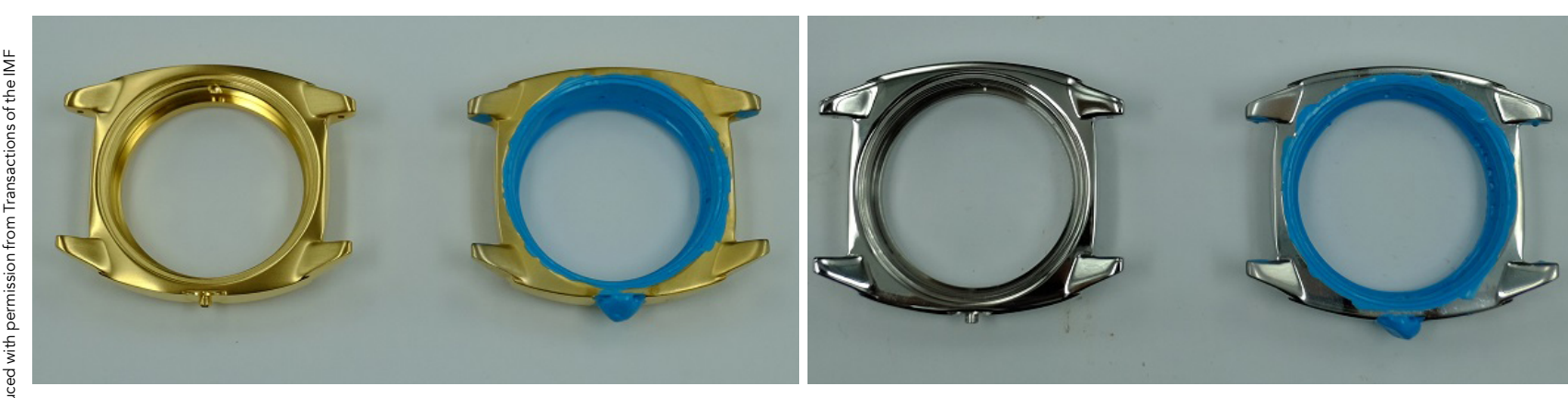

Nickel containing austenitic stainless-steel watch cases were submitted to the approved CEN nickel release tests, with nonsignificant surfaces masked as
shown in accordance with the specified test method.

Research Objectives

Clive Whittington and Dr Lo's work looks at ways to prevent nickel allergy.

\section{Detail}

Bio

Clive is a Chartered Professional Engineer, Fellow of the Institute of Materials Finishing (UK) and Managing Director of C. M. Whittington and Associates Ltd in Hong Kong and Melbourne, distributing nickel to manufacturers in Asia.

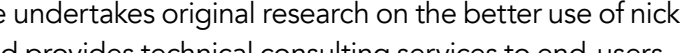

DrWilliam Lo is focused on industrial surface finishing, materials technology and testing, especially applied R\&D, technology transfer in production and waste minimisation technology. He is a Fellow of the Institute of Materials Finishing (UK) and has worked as a technical adviser and industrial consultant in the surface finishing industry

Funding

ckel Institute in these studies is acknowledged.

\section{Personal Response}

\section{What first sparked your interest in nickel allergy} and the preva

II Manufacturers in Asia are major suppliers of

consumer items to Europe, and if independent testing identifies that nickel release exceeds the CEN test limits, they cannot be placed on the market. To ensure product designers, manufacturers and merchandisers Europe this work was undertaken to provide peer reviewed guidelines to industry.

\section{References}

C.M. Whittington, W.Y. Lo and M.Y. Yau (2015) Prevention of nickel release from decorative nickel-chromium electroplated articles in the context of allergic contact dermatitis, Transactions of the IMF, 93, 176- 179. https:///
www.tandfonline.com/doiffull/10.1179/002029671 wZw.tandfonline.com/

C.M. Whittington and W.Y. Lo (2018) Prevention of nickel release from electroplated articles in the context of allergic
contact dermatitis: further outcomes, Transactions of the IMF, 96, 63-70. https://www.tandfonline.com/doiffull/10.1080/00 202967.2018.1426179

C.M. Whittington and W.Y. Lo (2019) 'Nickel Allergy' arising from decorative nickel plated and alloyed articles: prevention at source, Transactions of the IMF, 97, 64- 66. https://www.
tandfonline.com/doi/full/10.1080/00202967.2019.1570737

NHS (2016). Contact Dermatitis - Causes. [online] NHS Health A to Z. Available at: https://www.nhs.uk//conditions/contact-

National Eczema Society UK. (2019). Contact. [online] National Eczema Society. Available
[Accessed 15 July 2019].

Whittington, C. M. (2019). Research works produced by C. M. Whittington.[online] Available at: https://Www.researchgate. [Accessed 15 July 2019]

Calico Coatings. (2019). Titanium Nitride (TiN) PVD Coating. Calico Coatings. [online] Available at: https://www. calicocoatings.com/coating-data-Sheets/titanium-nitride-pve- 